\title{
$\therefore$ \\ Relationship between Thyroid Disorder and Abnormal Menstrual Bleeding
}

\section{IJCRR}

Section: Healthcare

ISI Impact Factor

(2019-20): 1.628

IC Value (2019): 90.81

$\operatorname{SJIF}(2020)=7.893$

(c) (7) (8)

Copyright@IJCRR

\section{Anjana Chaudhary ${ }^{1}$, Baljeet Kaur Bhatia ${ }^{2}$}

\author{
'Associate Professor Department of Obstetrics and Gynecology Chandulal Chandrakar Memorial Medical College, Kachandur, Durg, \\ Chhattisgarh-490024, India; ${ }^{2}$ Assistant Professor Department of Obstetrics and Gynecology Shri Shankaracharya Institute of \\ Medical Sciences Junwani, Bhilai, Chhattisgarh-490020, India.
}

\section{ABSTRACT}

Introduction: Menstrual disorders pose a huge burden on gynaecology OPD, accounting for approximately $20 \%$ of attendance of OPD. Thyroid disorders are prevalent globally, and thyroid conditions are 10 times more prevalent in women than in men. Thyroid dysfunction can prompt menstrual problems and infertility. Thyroid autoimmunity is associated with different forms of thyroid dysfunction.

Objective: To assess the relationship between thyroid disorder and abnormal menstrual bleeding.

Methods: Study was conducted in 100 women (age 15-45 years) suffering with menstrual disorders. Women with complaints other than menstrual disorders were in the control category. Following demographic characteristics, general physical examination and pelvic examination were performed with special reference to thyroid dysfunction. Patients were subjected to routine investigations (to rule out coagulation defects) such as $\mathrm{Hb}, \mathrm{BT}, \mathrm{CT}$ and platelets. All patients were subjected to Electro Chemiluminescence assay for T3, T4 and TSH estimation in their serum.

Results: Off all the kinds of menstrual irregularities, woman with amenorrhea, menorrhagia, oligomenorrhea, polymenorrhea and metrorrhagia were recorded. $55 \%$ of the cases in the study group were euthyroid while $45 \%$ of the cases were diagnosed with having thyroid disorder. In study group out of 45 cases having thyroid disorder of which 18 (18\%) were overt hypothyroid and $11(11 \%)$ were subclinical hypothyroid. Overt Hyperthyroid were $11(11 \%)$ and subclinical hyperthyroid were $5 \%$ in the study group. Of the total 3 amenorrhea cases $2(2 \%)$ were euthyroid while 1 case was hypothyroid. Out of 52 menorrhagia cases, 28 were euthyroid, 14(14\%) were hypothyroid and 10 (10\%) were hyperthyroid. 19 were oligomenorrhea cases of which 7 (7\%) each were euthyroid and hypothyroidism while one case was hyperthyroid.

Conclusion: Strong correlation of thyroid dysfunction with menstrual disorders has been observed. Morbidity due to thyroid dysfunction in women can be reduced if diagnosed timely and treated accordingly and unnecessary hormonal treatment and surgery can be avoided.

Key Words: Pelvic, Menstrual irregularities, Oligomenorrhea, Polymenorrhea, Metrorrhagia

\section{INTRODUCTION}

Menstruation is a natural phenomenon regarding the discharge of blood from the uterus through the vagina, taking place at extra or less regular monthly durations during the reproductive age of females. ${ }^{1}$ Menstrual disorders pose a huge burden on gynaecology OPD, accounting for approximately $20 \%$ of attendance. ${ }^{2}$ It has been described clinically in different ways, such as menorrhagia, metrorrhagia, menometrorrhagia, polymenorrhea, polymenorrhagia and oligomenorrhea. ${ }^{3}$ Normal cyclic period results from the arranged connection between the endometrium and its managing fac- tors. Changes in both of these oftentimes bring about strange bleeding. It influences up to $33 \%$ of ladies of childbearing age. $^{4}$

Thyroid hormones assume a significant part in reproductive physiology through direct impacts on the ovaries and by implication by communicating with sex hormone-binding globulin. Thyroid dysfunction can prompt menstrual problems and infertility. ${ }^{5}$ The onset of thyroid disorders is growing with age, and $26 \%$ of premenopausal and menopausal women are reported to be diagnosed with thyroid disease. ${ }^{6}$ Thyroid disorders are prevalent globally, and thyroid

\section{Corresponding Author:}

Dr. Anjana Chaudhary, Associate Professor Department of Obstetrics and Gynecology, Chandulal Chandrakar Memorial Medical College, Kachandur, Durg, Chhattisgarh-490024, India; Email: msaber@niles.edu.eg

ISSN: 2231-2196 (Print) ISSN: 0975-5241 (Online)

Received: $02.10 .2020 \quad$ Revised: 04.11 .2020

Accepted: 28.11 .2020

Published: 16.01 .2021 
conditions are 10 times more prevalent in women than in men. ${ }^{7}$ Since the 1950s, the effect of hypothyroidism on the menstrual cycle has been recognised, leading to changes in cycle length and blood flow. ${ }^{8}$ Menorrhagia is commonly observed in women with hypothyroidism. On the other hand, hyperthyroidism is associated with amenorrhea and oligomenorrhea, and the drop in flow is proportional to the magnitude of thyrotoxicosis. ${ }^{9}$

Thyroid autoimmunity is associated with different forms of thyroid dysfunction. Operational intervention such as curettage and hysterectomy may be prevented through early diagnosis of thyroid dysfunction in patients with menstrual disorders and their management. ${ }^{10}$

\section{MATERIALS AND METHODS}

The current research was performed in the Department of Obstetrics and Gynecology. 100 women each from the 1545-year reproductive age group were chosen in the study as well as in the control group. The research group included women with menstrual disorders such as menorrhagia, oligomenorrhea, polymenorrhea, metrorrhagia, hypomenorrhea and amenorrhea and no detectable disease in the genital tract. Women with complaints other than menstrual disorders were in the control category. The research excluded patients with a menstrual disorder with any known organic pathology, such as uterine fibroid, adenomyosis, tuberculosis, polyps, uterine malignancy, etc., and patients with intrauterine contraceptive device in utero.

Detailed demographic and personal history regarding age, parity, age of menarche, menstrual disorders and dysmenorrhea was taken. In women with menstrual complaints, general physical examination and pelvic examination were performed with special reference to thyroid dysfunction; in cases with a provisional diagnosis of AUB. To rule out the structural causes associated with menstrual irregularities, ultrasonography (USG-Abdomen and Pelvis with endometrial thickness) was performed. Patients were subjected to routine investigations (to rule out coagulation defects) such as $\mathrm{Hb}$, BT, CT and platelets. All patients were subjected to Electro Chemiluminescence assay for T3, T4 and TSH estimation in their serum.

If TSH, T3, and T4 were within the normal range (TSH level $=0.39-6.16 \mu \mathrm{IU} / \mathrm{ml}$, free T3 level $=1.4-4.2 \mathrm{pg} / \mathrm{ml}$, and free T4 level $=0.8-2.0 \mathrm{ng} / \mathrm{ml}$ ), patients were considered as euthyroid; when TSH was elevated with T3 and T4 below the normal range, they were classified as subclinical hypothyroidism. Overt hypothyroidism was diagnosed with high TSH and low levels of T3 and T4, subclinical hyperthyroidism with low TSH and normal levels of T3 and T4, and overt hyperthyroidism with low levels of TSH and high levels of $\mathrm{T} 3$ and $\mathrm{T} 4$.
Statistical analysis was done, for qualitative data to measure p-value, Chi-square test and Fisher exact test was used, and unpaired student t-test and non-parametric Wilcoxon-MannWhitney test were used to statistically compare the quantitative data between two classes for T3, T4, TSH, and anti-TPO antibody values. The difference was deemed statistically significant with a p-value of $<0.05$.

\section{RESULTS}

Various parameters analyzed were

- Age

- Parity

- Menstrual irregularities

- Thyroid status

- Association of menstrual irregularities with thyroid dysfunction.

The study and control groups were comparable in respect of age

Of all the kinds of menstrual irregularities, 3 (3\%) had amenorrhea, 52 (52\%) had menorrhagia, 19 (19\%) had oligomenorrhea, $15(15 \%)$ had polymenorrhea and $11(11 \%)$ had metrorrhagia (Table 1).

$55 \%$ of the cases in the study group were euthyroid while $45 \%$ of the cases were diagnosed with having thyroid disorder. While in the control group $85 \%$ of the cases were euthyroid while $15 \%$ were having a thyroid disorder.

\section{Table 1: Menstrual Irregularities}

\begin{tabular}{lcc} 
Irregularities & $\mathbf{n}$ & $\%$ \\
Amenorrhea & 3 & $3 \%$ \\
Menorrhagia & 52 & $52 \%$ \\
Oligomenorrhea & 19 & $19 \%$ \\
Polymenorrhea & 15 & $15 \%$ \\
Metrorrhagia & 11 & $11 \%$ \\
Total & 100 & $100 \%$ \\
\hline
\end{tabular}

In study group out of 45 cases having thyroid disorder of which $18(18 \%)$ were overt hypothyroid and $11(11 \%)$ were subclinical hypothyroid. Overt Hyperthyroid were 11 (11\%) and subclinical hyperthyroid were $5 \%$ in the study group. In the control group, one (1\%) case was overt hypothyroid and $8(8 \%)$ were subclinical hypothyroid, while $4(4 \%)$ were over hyperthyroid and $2(2 \%)$ ware subclinical hyperthyroid.

Thyroid anti-TPO antibodies were present in 25 (25\%) of the cases in the study group as compared to $3(6 \%)$ cases in the control group. This difference was statistically significant $(\mathrm{p}<0.005)$ (Table 2). 
Table 2: Thyroid disorder in the study and control group

\begin{tabular}{lcccc} 
Thyroid status & \multicolumn{2}{c}{ Study group } & \multicolumn{2}{c}{ Control group } \\
& $\mathbf{n}$ & $\%$ & $\mathbf{N}$ & $\%$ \\
Euthyroid, & $\mathbf{5 5}$ & $\mathbf{5 5 \%}$ & $\mathbf{8 5}$ & $\mathbf{8 5 \%}$ \\
Overt Hypothyroid & 18 & $18 \%$ & $\mathbf{1}$ & $\mathbf{1} \%$ \\
Subclinical Hypothyroid & $\mathbf{1 1}$ & $\mathbf{1 1} \%$ & 8 & $8 \%$ \\
Overt Hyperthyroid & 11 & $11 \%$ & 4 & $4 \%$ \\
Subclinical Hyperthyroid & 5 & $5 \%$ & $\mathbf{2}$ & $\mathbf{2} \%$ \\
\hline
\end{tabular}

Of the total 3 amenorrhea cases $2(2 \%)$ were euthyroid while 1 case was hypothyroid. Out of 52 menorrhagia cases, 28 were euthyroid, 14(14\%) were hypothyroid and $10(10 \%)$ were hyperthyroid. 19 were oligomenorrhea cases of which $7(7 \%)$ each were euthyroid and hypothyroidism while one case was hyperthyroid. Out of 11 metrorrhagia cases, $6(6 \%)$ were euthyroid, $4(4 \%)$ were hypothyroid while $1(1 \%)$ case was hyperthyroid ( Table 3).

Table 3: Thyroid dysfunction and menstrual disorder.

\begin{tabular}{lcccc} 
Irregularities & $\mathbf{N}$ & $\begin{array}{c}\text { Euthyroid } \\
\mathbf{N}=55\end{array}$ & $\begin{array}{c}\text { Hypo- } \\
\text { thyroid } \\
\mathbf{N}=29\end{array}$ & $\begin{array}{c}\text { Hyper- } \\
\text { thyroid } \\
\mathbf{N}=16\end{array}$ \\
Amenorrhea & 3 & 2 & 1 & 0 \\
Menorrhagia & 52 & 28 & 14 & 10 \\
Oligomenorrhea & 19 & 12 & 3 & 4 \\
Polymenorrhea & 15 & 7 & 7 & 1 \\
Metrorrhagia & 11 & 6 & 4 & 1 \\
Total & 100 & 55 & 29 & 16 \\
\hline
\end{tabular}

\section{DISCUSSION}

Thyroid problems in general and hypothyroidism in particular is more commonly seen in women of reproductive age. ${ }^{7,8}$ Reproductive years and menopausal years are significantly influenced by the thyroid status of the women. Hypo and hyperthyroidism, both are associated with menstrual disturbances although hormonal and other biochemical aberrations are different. ${ }^{9,10}$ Thyroid status of the women influences the menarche, pubertal growth and development, fertility and foetal development, menstrual cycles, postpartum period, reproductive years, and postmenopausal years.

In our study, $53 \%$ of the cases were observed with menorrhagia which was the most common complaint among the patients with menstrual disorders. Similar observations were seen in other studies of Pahwa et al. ${ }^{11}(50 \%)$ and Padmaleela et al. ${ }^{12}$ (50\%), where menorrhagia was the most common complaint. In the present study, $55 \%$ were euthyroid in study group while $85 \%$ were euthyroid in the control group. This shows the commonness of hypothyroidism and hyperthyroidism in patients with menstrual problems is very nearly two times higher than in the control population. Kaur et al. ${ }^{13}$ observed that $14 \%$ of the cases had hypothyroidism while in the study by Pahwaa et al. ${ }^{11} 22 \%$ cases of hypothyroidism and $76 \%$ of euthyroidism were reported. Gowri et al. ${ }^{14}$ observed $17.6 \%$ women with hypothyroidism, $2.7 \%$ with subclinical hypothyroidism, and $4.7 \%$ with hyperthyroidism.

In the present study of the total 3 amenorrhea cases, $2(2 \%)$ were euthyroid while 1 case was hypothyroid. Out of 52 menorrhagia cases, 28 were euthyroid, 14(14\%) were hypothyroid and $10(10 \%)$ were hyperthyroid. 19 were oligomenorrhea cases of which $7(7 \%)$ each were euthyroid and hypothyroidism while one case was hyperthyroid. Out of 11 metrorrhagia cases, $6(6 \%)$ were euthyroid, 4 (4\%) were hypothyroid while $1(1 \%)$ case was hyperthyroid. Kaur et al. ${ }^{13}$ observed that the patient with hyperthyroidism was found to have hypomenorrhea. Pahwa et al. ${ }^{11}$ in their study observed that two hyperthyroid patients, both had menorrhagia. While Padmaleela et al. ${ }^{12}$ observed that among the hyperthyroid patients, $42.8 \%$ had menorrhagia, $28.6 \%$ had polymenorrhea, and $14.3 \%$ had oligomenorrhea.

\section{CONCLUSION}

In this study, a strong correlation of thyroid dysfunction with menstrual disorders has been observed. Morbidity due to thyroid dysfunction in women can be reduced if diagnosed timely and treated accordingly and unnecessary hormonal treatment and surgery can be avoided.

\section{ACKNOWLEDGMENT}

Authors acknowledge the immense help received from the scholars whose articles are cited and included in references to this manuscript. The authors are also grateful to authors / editors / publishers of all those articles, journals, and books from which the literature for this article has been reviewed and discussed.

\section{Conflict of Interest: Nil}

\section{Source of Funding: Nil}

\section{REFERENCES}

1. House S, Mahon T, Cavill S, editors. Menstrual hygiene matters. A resource for improving menstrual hygiene around the world. Module one: Menstrual hygiene -the basics. www.wateraid.org/ /media/Files/Global/MHM\%20files/Compiled_L

2. Albers JR, Hull SK, Wesley RM. Abnormal uterine bleeding. Am Fam Physician 2004; 69(8):1915-26.

3. Talukdar B, Mahela S. Abnormal uterine bleeding in perimenopausal women: Correlation with sonographic findings and histo- 
pathological examination of hysterectomy specimens. J Midlife Health 2016;7(2):73-77.

4. Nicholson WK, Ellison SA, Grason H, Powe NR. Of ambulatory care use for gynecologic conditions; A national study. Am J Obstet Gynecol 2001;184(4):523-530.

5. Poppe K, Glinoer D. Thyroid autoimmunity and hypothyroidism before and during pregnancy. Hum Reprod Update 2003;9(2):149-161.

6. Hollowell JG, Staehling NW, Flanders WD, Hannon WH, Gunter EW, Spencer CA, et al. Serum TSH, T(4), and thyroid antibodies in the United States population (1988 to 1994): National Health and Nutrition Examination Survey (NHANES III). J Clin Endocrinol Metab 2002; 87(2):489-499.

7. Cappola AR, Ladenson PW. Hypothyroidism and atherosclerosis. J Clin Endocrinol Metab 2003;88(6):2438-2344.

8. Bals-Pratsch M, De Geyter C, Müller T, Frieling U, Lerchl A, Pirke KM, Hanker JP, Becker-Carus C, Nieschlag E. Episodic variations of prolactin, thyroid-stimulating hormone, luteinizing hormone, melatonin and cortisol in infertile women with subclinical hypothyroidism. Hum Reprod 1997;12(5):896-904.
9. Manjeera LM, Kaur P. Association of thyroid dysfunction with abnormal uterine bleeding. Int J Reprod Contracept Obstet Gynecol 2018;7:2388-2392.

10. Ajmani NS, Sarbhai V, Yadav N, Paul M, Ahmad A, Ajmani AK. Role of Thyroid Dysfunction in Patients with Menstrual Disorders in Tertiary Care Center of Walled City of Delhi. J Obstet Gynaecol 2016;66(2):115-119.

11. Pahwa S, Shailja G, Jasmine K. Thyroid dysfunction in dysfunctional uterine bleeding. J Adv Res Bio Sci 2013;5(1):78-83.

12. Padmaleela K, Thomas V, Lavanya KM. Thyroid disorders in dysfunctional uterine bleeding (DUB) among reproductive age group women- a cross-sectional study in a tertiary care hospital in Andhra Pradesh India. Int J Med Pharma Sci 2013;4(1):41-46.

13. Kaur T, Aseeja V, Sharma S. Thyroid dysfunction in dysfunctional uterine bleeding. Web Med Central Obstet Gynaecol 2011;2(9):1-7.

14. Gowri M, Radhika BH, Harshini V. Role of thyroid function tests in women with abnormal uterine bleeding. Int J Reprod Contracept Obstet Gynecol 2014;3(1):54-57. 